\title{
DICIONÁRIOS BIZARROS: FRAGMENTOS POÉTICOS DE EXPERIÊNCIAS
}

\author{
Gizelle Kaminski Corso* \\ Instituto Federal de Santa Catarina
}

\begin{abstract}
Resumo: Este artigo objetiva apresentar a atividade desenvolvida no Instituto Federal de Educação, Ciência e Tecnologia de Santa Catarina (IFSC) - Campus Florianópolis, inspirada no livro de literatura infantojuvenil, Mania de explicação, de Adriana Falcão e Mariana Massarani. Essa atividade consiste na elaboração de dicionários - Dicionários Bizarros - por estudantes de Cursos Técnicos Integrados ao Ensino Médio cujos verbetes, e seus respectivos significados sentidos, soam como poemas e são fragmentos poéticos de suas experiências. No primeiro momento do texto, apresentam-se algumas reflexões a respeito do livro Mania de explicação e do ensino de língua portuguesa e de literatura, bem como o histórico da proposta, abordando-se motivações, dificuldades e considerações sobre a atividade desenvolvida. No segundo momento, tendo por base o conceito de experiência, do professor e pesquisador Jorge Larrosa (2002), faz-se uma análise de alguns trabalhos realizados por estudantes dessa escola técnica federal e dos significados elaborados para os verbetes em seus dicionários.
\end{abstract}

Palavras-chave: Dicionário bizarro. Experiência. Literatura e ensino.

\section{Palavras iniciais}

Em 2012, ano em que atuei como professora de Metodologia de Ensino da Língua Portuguesa e Literatura, na Universidade Federal de Santa Catarina, uma das acadêmicas trouxe para um encontro o livro Mania de explicação (2001), de Adriana Falcão, com ilustrações de Mariana Massarani. Naquele momento da disciplina, estávamos discutindo sobre a necessidade e a validade das diferentes adjetivações da literatura (infantil, infantojuvenil, juvenil) e em propostas de atividades de leitura para leitores de todas as idades. Nessa discussão, vislumbramos a possibilidade de realizar atividades em sala com o referido livro envolvendo leitores de todas as idades.

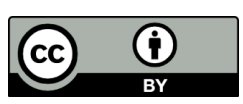

\section{Esta obra está licenciada sob uma Creative Commons - Atribuição 4.0}

\footnotetext{
* Possui graduação em Letras Português - Espanhol e Respectivas Literaturas pela Universidade do Oeste de Santa Catarina (2003), graduação em Letras Língua Italiana e Literaturas pela Universidade Federal de Santa Catarina (2007), mestrado em Literatura e Vida Social pela Universidade Estadual Paulista Júlio de Mesquita Filho (2007) e doutorado em Teoria Literária pela Universidade Federal de Santa Catarina (2012). Atualmente é professora efetiva do Instituto Federal de Santa Catarina e Coordenadora dos Cursos Técnicos Integrados. Possui experiência na área de Letras com ênfase em Teoria Literária, atuando principalmente nos seguintes temas: adaptação; clássico; literatura e ensino; literatura infantojuvenil; leitor, leitura. E-mail: gizelle.corso@ifsc.edu.br.
} 
O livro Mania de explicação (2001) consiste em explicações, feitas pela personagem principal, uma menina, de tudo aquilo que a rodeia. Além disso, ela vê, nas simplificações, um meio de facilitar diversas situações da vida dentro de sua cabeça. A forma pela qual o livro é organizado faz com que leitores recordem-se de um dicionário por apresentar diversos "verbetes" - alguns deles bastante poéticos - e suas respectivas explicações. No entanto, diferentemente da lógica alfabética do $\mathrm{A}$ ao Z, as palavras são dispostas, aparentemente, de maneira aleatória, mas, de fato, estão entrelaçadas umas às outras, compondo uma narrativa: "Essa menina pensa que é filósofa, as pessoas falavam" e ela explicava: "Filósofo é quem, em vez de ver televisão, prefere ficar pensando pensamentos" (FALCÃO, 2001, s/p).

Para a personagem, as palavras que surgem, em diferentes contextos e situações, geralmente servem de gancho para explicações que procuram tornar o mundo mais bonito. E o verbete "explicação", como não poderia ficar de fora, segundo ela, é compreendido da seguinte forma: "Explicação é uma frase que se acha mais importante do que a palavra" (FALCÃO, 2001, s/p).

Com ares de filósofa sem a pretensão de o ser, a menina procura dar uma seiva, vigor e teor diferente para as palavras, atribuindo a elas sentidos distintos a partir da elaboração de seus significados - daquilo que elas passam a significar para a personagem:

De tanto que a menina explicava, as pessoas às vezes se irritavam, (irritação é um alarme de carro que dispara bem no meio do seu peito) e terminavam indo embora, deixando a menina lá, explicando, sozinha. (FALCÃO, 2001, s/p).

Embora haja um emaranhado de explicações e estas não se apresentem isoladamente, foi este livro que serviu de "mote" para uma atividade que desenvolvo, em minhas aulas de "Português e História da Literatura Brasileira", com estudantes do Ensino Médio Integrado, no Instituto Federal de Santa Catarina, desde o primeiro semestre de 2014.

A atividade, intitulada "Dicionário Bizarro", consiste na composição de um Dicionário em que os estudantes devem escolher, no mínimo, 20 palavras e elaborar o significado a partir do sentido, daquilo que elas significam para eles, ou seja, do "significado sentido". Intitulei-o "Bizarro" porque a proposta é aberta e permite a inclusão de gírias, expressões, neologismos, palavras preferidas, palavras que até então thes são desconhecidas, interjeições, enfim, uma miscelânea - que justifica o seu título. Não tem, também, o compromisso de igualar-se a um Dicionário, seguir lógica alfabética, classificações gramaticais acerca dos verbetes, numeração de páginas, entre outros. Eles podem lançar mão da criatividade, escrever a mão, com papéis de diferentes texturas, cores, incluir ilustrações, iluminuras; se preferirem, podem utilizar o computador, fontes e tamanhos diversificados. 
Ainda, esta atividade é encaminhada quando ocorre a leitura e discussão do Plano de Ensino, no início do semestre, e só deve ser entregue no final. Portanto, a ideia é que o Dicionário seja elaborado paulatinamente, pois, durante algumas aulas, costumo chamar a atenção para algumas palavras, contextos de uso, e de lembrá-los acerca da atividade.

No primeiro ano em que a apliquei, os estudantes ficaram entusiasmados com a proposta, mas o resultado não foi completamente satisfatório porque poucos exploraram os significados sentidos das palavras e os verbetes estavam praticamente colados às definições presentes nos Dicionários Houaiss ou Aurélio, por exemplo, e/ou de diversos dicionários de gírias ou expressões disponíveis na Internet. Além disso, mais da metade da turma elaborou o dicionário nos moldes da ABNT, provavelmente, influenciada pela unidade curricular Projeto Integrador 1 - parte diversificada -, que objetiva a iniciação à pesquisa científica e na qual apre(e)ndem as normas técnicas para a confecção de trabalhos acadêmicos.

Ao refletir sobre o veemente entusiasmo dos estudantes contrapondo-o ao resultado inesperado, concluí que a falha residia justamente em mim, melhor dizendo, na fala, no encaminhamento da proposta. Então, no ano seguinte, trouxe para a sala de aula o livro Mania de explicação, mostrei-o aos estudantes e li alguns dos "verbetes", destacando dentre eles o de solidão: "Solidão é uma ilha com saudade de barco" (FALCÃO, 2001, s/p). Além disso, procurei trazer outros exemplos para que pudessem visualizar aquilo que lhes era proposto com mais facilidade. A partir disso, criou-se um momento propício para discussão e, consequentemente, ampliação dos seus horizontes.

\section{Os dicionários bizarros e o ensino-aprendizagem}

"Por que estudar Português quando esta é a minha língua materna? Ler e escrever, para quê? Literatura, por quê?” Estes são alguns dos questionamentos comumente feitos por alguns estudantes em aulas de Português e História da Literatura Brasileira. Sem pretensões de esgotar a discussão e de reduzir a resposta a uma única possibilidade, são trazidas para o debate questões referentes à promoção da potencialização das práticas de uso da língua(gem) - em interações situadas histórica e culturalmente - nas diferentes esferas da atividade humana, com vistas a ampliar suas experiências discursivas, textuais, gramaticais e de letramento.

Portanto, na discussão, são trazidas à tona concepções - embora não "nominadas" aos estudantes - acerca do ensino-aprendizagem do Português, que estão centradas nos pressupostos da teoria sociointeracionista (BAKHTIN, 1990), a concepção de linguagem como interação, mediada pela noção de gêneros do discurso. Além disso, por meio de práticas 
que envolvem, de forma integrada, a fala e a escuta, bem como a leitura e a escrita (GERALDI, 2006), pretende-se evitar a artificialidade no uso da língua e possibilitar o domínio em diferentes situações de comunicação que não estejam restritas a uma variedade.

Neste sentido, a elaboração de um Dicionário Bizarro demanda percepção dos estudantes que perpassa os eixos de uso e reflexão da língua, transcendendo os limites da sala de aula. Considerando que os dicionários podem - e devem - contemplar "verbetes" que pressuponham diversos contextos de uso da língua, suas escolhas são pautadas por preferências, apego a palavras, gírias próprias de seus pares e atenção para a descoberta de novas palavras. Ainda, tendo em vista que o Dicionário deve ser elaborado durante o semestre, os estudantes tornam-se vigilantes nos textos - especialmente nos textos literários -, nos debates realizados nas aulas e manifestam-se constantemente à guisa de dúvidas: "Professora, mas esta palavra, então, poderia estar no Dicionário?"

É pela liberdade da proposta de trabalho que ocorre a ampliação do olhar a respeito da língua porque envolve suas vivências e experiências com a linguagem. Suas manifestações são diversas: "Na minha antiga escola, a professora de português fazia a gente ficar decorando as orações subordinadas, bem que ela poderia ter encaminhado isso, né!", e por meio de perguntas: "Dá pra colocar termos de jogo, expressões que usamos lá em casa e ilustrar, professora?" "Mas e se eu quiser fazer no computador e não colocar em ordem alfabética, pode?" À medida que as respostas lhes soam afirmativas, o entusiasmo cresce, provavelmente, pela desconstrução da ideia que concebem de um Dicionário: em síntese, um livro que apresenta uma compilação de unidades léxicas de uma língua e suas definições, que devem estar dispostas em ordem alfabética. Embora tenham autonomia para escolher os verbetes, disposição, formato, por exemplo, precisam seguir três orientações: elaborar os significados das palavras a partir do significado que elas têm para eles, atender a quantidade mínima de verbetes para a composição do dicionário e lançar mão da criatividade. E, em virtude dessa liberdade - palavra, inclusive usada por alguns estudantes em aula -, muitos verbetes possuem alta carga poética, sendo possível demonstrar a elas e a eles que também são produtores de Literatura, ou seja, que seus verbetes são fragmentos poéticos de suas experiências. Saliento que é na primeira fase do curso que os estudantes estudam os conceitos de Literatura, de texto literário, refletindo sobre eles. E os dicionários bizarros auxiliam significativamente neste processo.

\section{As bizarrices, os verbetes}

A atividade Dicionário Bizarro procura proporcionar a ampliação do olhar a respeito 
da língua porque permite envolver experiências dos estudantes com a linguagem. E, quando me refiro ao conceito de experiência, valho-me das reflexões tecidas por Jorge Larrosa (2002), daquilo que nos fica, nos passa, e não daquilo que, simplesmente, fica ou passa. De acordo com Larrosa (2002), a informação, a falta de tempo, o excesso de opinião e o excesso de trabalho não deixam espaço para a experiência e, consequentemente, para a memória, porque tudo acontece muito rápido, veloz, fugaz. Melhor dizendo, deve-se absorver o máximo de informação, digeri-la rapidamente, ter uma opinião sobre, aproveitar o máximo do tempo e fazer o máximo em menos tempo possível. Diferentemente, a experiência

\begin{abstract}
requer um gesto de interrupção, um gesto que é quase impossível nos tempos que correm: requer parar para pensar, parar para olhar, parar para escutar, pensar mais devagar, olhar mais devagar, e escutar mais devagar; parar para sentir, sentir mais devagar, demorar-se nos detalhes, suspender a opinião, suspender o juízo, suspender a vontade, suspender o automatismo da ação, cultivar a atenção e a delicadeza, abrir os olhos e os ouvidos, falar sobre o que nos acontece, aprender a lentidão, escutar aos outros, cultivar a arte do encontro, calar muito, ter paciência e dar-se tempo e espaço. (LARROSA, 2002, p. 24).
\end{abstract}

A experiência, como demonstra Larrosa, demanda um gesto de interrupção, de lentidão, de paciência. Por isso, o máximo de tempo possível - dentro da lógica semestral para a elaboração dos dicionários e o mínimo de imposições; para que se possa escolher, olhar, escutar, perceber, demorar-se nos detalhes, desligar-se do automatismo; para que se possa cultivar a atenção às palavras, aos seus possíveis significados sentidos - seja a partir da sonoridade, da ambiguidade, do apego, do uso, seja a partir do desafio de aventurar-se na percepção e na atribuição de outro significado que supere as constantes definições dos dicionários, que rompa com o pré-concebido.

Como há um mínimo de verbetes - vinte -, é possível perceber que essa escolha é cuidadosa e amparada em afetos, desafetos, afinidades, experiências arriscadas, perigosas, conforme nos lembra Larossa a respeito da etimologia da palavra, quando diz:

A palavra experiência vem do latim experiri, provar (experimentar). A experiência é em primeiro lugar um encontro ou uma relação com algo que se experimenta, que se prova. O radical é periri, que se encontra também em periculum, perigo. A raiz indo-europeia é per, com a qual se relaciona antes de tudo a ideia de travessia, e secundariamente a ideia de prova. (2002, p. 25).

E, nesse percurso, é possível perceber que os verbetes atravessam os estudantes e estes também são atravessados pelos significados sentidos que elaboram. Além disso, esses significados soam como poemas, pois exploram aspectos diversos de linguagem, apresentam trocadilhos, rimas, e traduzem, em alguns momentos, seus modos de ser, de se colocar no 
mundo e de senti-lo ou de se sentirem como parte dele. Os verbetes, também, rompem com aquilo que se esperaria da definição de uma palavra em um dicionário, adentram outros espaços e percorrem diversos caminhos, como é possível perceber nos exemplos a seguir, retirados de dicionários de alguns estudantes.

O primeiro dicionário a ser mencionado é o elaborado por Maria Luiza Serpa Casagrande de Oliveira, estudante do Curso Técnico em Química Integrado ao Ensino Médio, que o intitula de Meu dicionário bizarro, tornando veemente, com o uso do possessivo, uma indicação de proximidade e pessoalidade ao objeto. Os verbetes selecionados do seu dicionário envolvem os significados sentidos para as palavras "Mentira" e "Monices":

\author{
MENTIRA \\ Peças de um \\ quebra-cabeça forçadas \\ a se encaixarem. \\ (OLIVEIRA, 2015, s/p) \\ MONICES \\ Coisas \\ que \\ monos \\ fazem. \\ (OLIVEIRA, 2015, s/p).
}

Para Oliveira, o significado de "mentira" ultrapassa o previsto em dicionários: "ato ou efeito de mentir; não dizer a verdade", por exemplo, sendo compreendido a partir da percepção lúdica e metafórica de um jogo de quebra-cabeças, cujas peças são forçadas a se encaixarem; melhor dizendo, peças que não pertencem a esse jogo e, portanto, não deveriam estar ali. Em contrapartida, a palavra "monice", embora soe como um neologismo para aqueles que não estão no entorno do IFSC - na verdade, não o deixa de ser -, é uma palavra comumente usada no âmbito da referida instituição e "deriva" de "mono", um sinônimo para "calouro", "estudante de primeira fase". A origem do termo não é recente nessa escola técnica federal e se deve à tensão de corrente, monofásica, uma fase, sendo "monos" aqueles que estão na primeira fase de um curso. Da palavra mono, a estudante cria o substantivo "monice", fazendo referência às ações daqueles que são novos no meio acadêmico, partindo de sua experiência, de se ver como "mono" no momento em que elabora o dicionário.

Em outro verbete, a conjunção coordenativa "Ou”, Oliveira abre mão de definições gramaticais - e isso não ocorre por desconhecimento - para revelar possivelmente um pouco de si, por se ver em dúvidas em alguns momentos, o que se amplia inclusive para a elaboração

Anu. Lit., Florianópolis, v. 23, n. 1, p. 76-86, 2018. ISSNe 2175-7917 
do significado sentido para a referida palavra:

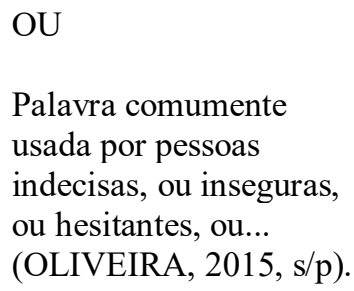

As reticências sinalizam o pensamento em suspensão e abrem margem para que os leitores completem a ideia para além do exposto. Embora a conjunção gramaticalmente sirva para unir orações e palavras indicando dúvida, incerteza, alternância, exclusão, segundo a Oliveira, "ou" é uma palavra muito usada tanto por pessoas indecisas quanto por pessoas inseguras e hesitantes, mas há muito além disso. E sua ponderação reside, justamente, nos pontos suspensivos, que permitem ampliar a percepção, não se restringindo a um isto ou um aquilo.

Em outro dicionário, elaborado por Kaori de Novaes Kawano, também estudante do Curso Técnico em Química Integrado ao Ensino Médio, há, a exemplo do anterior, várias palavras muito presentes em seu cotidiano, em sua experiência, e atribui a elas significados sentidos que, embora breves, são bastante peculiares no que diz respeito às palavras "tipo" e "coisa":

TIPO

Vírgula da oralidade.

(KAWANO, 2015, s/p).

\section{COISA COISA COISA}

Palavra substituta

(KAWANO, 2015, s/p).

A partir do seu olhar sensível a respeito da língua, a estudante extravasa o entendimento da palavra "tipo" que, em primeira mão, remete a classe, gênero, classificação, modelo, categoria por exemplo, e faz uma leitura da forma pela qual especialmente adolescentes costumam se comunicar: "Eu falei pra ela, tipo, que não estava bem". "Tô precisando de algo, tipo um...". A estudante parte para o eixo de uso e reflexão da língua no cotidiano e, valendo-se de um dos sinais de pontuação - a vírgula -, estabelece que "tipo", para ela, significa a "vírgula da oralidade", uma pausa, uma ruptura, uma palavra que interrompe as falas. O outro verbete - "coisa" - é compreendido pela estudante como palavra substituta, aquela usada para inumeráveis situações, e que vem, geralmente, no lugar da 
palavra esquecida, a ser lembrada, a inominada. Assim como os de Oliveira (2015), os verbetes de Kawano são fragmentos poéticos de suas experiências, pílulas poéticas, poemas curtos, que dificilmente excedem os 140 caracteres. Esses dois verbetes - e tantos outros do seu dicionário - foram incluídos ao livro publicado pela estudante em 2016, sob o título Palavras de uma criança, de uma menina, de uma adolescente, que inclui poemas, contos e crônicas, alguns resultantes de trabalhos escolares (como é o caso do Dicionário Bizarro), escritos por Kawano em diferentes fases de sua vida.

No dicionário do estudante Leonardo Madruga, do Curso Técnico em Eletrotécnica Integrado ao Ensino Médio, há verbetes que sinalizam um olhar cotidiano com teor sarcástico e irônico a respeito de suas vivências no âmbito da sala de aula, como é o caso dos significados sentidos para as disciplinas "Português" e "Matemática":

\title{
PORTUGUÊS
}

\author{
Escrever com estilo \\ muito estilo mesmo! \\ Pé de cabra voador \\ Se você fosse meu, \\ Meu amor \\ Pão de forma \\ Será de seu louvor. \\ (MADRUGA, 2015, s/p).
}

Para Madruga, a disciplina Português tem relação com o fato de alguém saber escrever bem, ter estilo, enfeitar a escrita. Para endossar sua ideia de estilo ironicamente, compõe um poema - à guisa de parecer nonsense - dando pouca ênfase ao fundo, à produção de sentidos, e muita ênfase à forma, à estrutura: um texto em versos, com rimas, vocativo amoroso, que se pretende elegante. Na mesma linha, elabora o seguinte significado sentido para a disciplina "Matemática":

\section{MATEMÁTICA}

Lógica:

$$
1+1=\frac{\sqrt{\Delta}}{\mathrm{y}} \cdot \operatorname{sen} \cdot \sum o^{2}-\mathrm{K}
$$

Quantos pães foram vendidos?

R: Maria tem doze anos. (MADRUGA, 2015, s/p). 
"Matemática" é aparentemente "ilógica" pelo cálculo que apresenta. Ainda, no bojo de suas reflexões, traz, para a composição do significado, uma pergunta que relembra uma questão de prova, elemento cotidiano de estudantes, por meio da qual há o questionamento: "Quantos pães foram vendidos?" e a resposta, novamente nonsense, que diz: "Maria tem doze anos". Embaixo da resposta, acrescenta-se a ilustração do sinal de certo, feito com outra cor possivelmente por um professor -, que aponta estar correta a resolução da questão.

Diferentemente dos trabalhos anteriores, no dicionário da estudante Domenica Zatti, do Curso Técnico em Saneamento Integrado ao Ensino Médio, e nos significados sentidos que cria para os seus verbetes, há um olhar engajado e empoderado, por meio do qual viu uma oportunidade para apresentar desafetos e desfolhar-se em desabafos a respeito de diversos temas, predominantemente sociais, que pode ser percebida nos verbetes: "Invisível", "Cotidiano" e "Indiferença":

\section{INVISÍVEL}

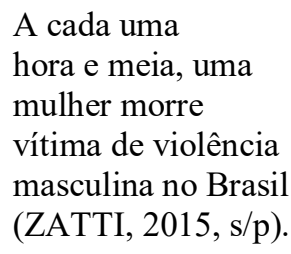

\section{COTIDIANO}

Panem et

Circenses

(ZATTI, 2015, s/p).

\section{INDIFERENÇA}

Sossegar o que não te afeta

Só cegar.

(ZATTI, 2015, s/p).

Para "invisível", aquilo que não tem visibilidade, que não pode ser visto, Zatti elabora um significado que contempla a invisibilidade das mulheres que sofrem violência masculina no Brasil. Seu verbete, que inicialmente lembra um dado estatístico, rompe a lógica dicionarizada, provoca os leitores e chama a atenção para a condição das mulheres violentadas e a invisibilidade delas, de suas dores, conflitos, dificuldades, problemas, diante da maioria.

Em relação a "cotidiano", ao criar o seu significado, procura restringi-lo a três palavras latinas: "panem et circenses", expressão popularmente conhecida em tradução como 
"pão e circo". Do mesmo modo, por meio desse significado, a estudante recupera o nome dado a uma política desenvolvida durante o Império Romano vista como uma medida para manipular as massas.

No que diz respeito ao significado de "indiferença", para o qual elabora criativamente um trocadilho com as palavras "sossegar" e "só cegar", Zatti chama a atenção para a cegueira das pessoas diante daquilo que não lhes afeta, o descaso e a falta de interesse em relação à situação dos outros.

Portanto, a potência dos verbetes dos Dicionários Bizarros reside justamente nos significados sentidos que são atribuídos a palavras e contemplam as vivências e experiências dos estudantes. Dão sentido àquilo que são, ao que os rodeia e ao que lhes acontece, como afirma Larrosa,

[...]. As palavras determinam nosso pensamento porque não pensamos com pensamentos, mas com palavras, não pensamos a partir de uma suposta genialidade ou inteligência, mas a partir de nossas palavras. E pensar não é somente "raciocinar" ou "calcular" ou "argumentar", como nos tem sido ensinado algumas vezes, mas é sobretudo dar sentido ao que somos e ao que nos acontece. E isto, o sentido ou o sem-sentido, é algo que tem a ver com as palavras (LARROSA, 2002, p. 20-21).

Seja pelo sentido, ou pelo sem-sentido, seja ele ou não contido, cada verbete incorpora e carrega em si um pouco daquele ou daquela que o idealizou e o concebeu. A articulação das palavras que o compõem, que o dignificam, que o significam, revelam um pouco desse sujeito, de suas percepções de mundo, e configuram-se como fragmentos poéticos de suas experiências.

\section{Referências}

BAKHTIN, Mikhail. Marxismo e filosofia da linguagem. 5.ed. São Paulo: Hucitec, 1990.

FALCÃO, Adriana. Mania de explicação. Ilustrações de Mariana Massarani. São Paulo: Moderna, 2001.

GERALDI, João Wanderley; ALMEIDA, Milton José de (Org.). [et al.]. O texto na sala de aula. 4.ed. São Paulo: Ática, 2006.

KAWANO, Kaori de Novaes. Dicionário bizarro. Florianópolis: IFSC, 2015.

. Palavras de uma criança, de uma menina, de uma adolescente. Edição da autora, Florianópolis, 2016.

LARROSA, Jorge. "Notas sobre a experiência e o saber de experiência". Revista brasileira de educação, Campinas, n. 19, p. 20-28, Jan/2002.

MADRUGA, Leonardo. Dicionário bizarro. Florianópolis: IFSC, 2015. 
OLIVEIRA, Maria Luiza Serpa Casagrande de. Meu dicionário bizarro. Florianópolis: IFSC, 2015.

ZATTI, Domenica. Dicionário Bizarro. Florianópolis: IFSC, 2015.

\section{Bizarre dictionaries: poetic fragments of experiences}

Abstract: This article aims to present the activity developed at the Federal Institute of Education, Science and Technology of Santa Catarina (IFSC) - Campus Florianópolis, inspired by the book of children's literature, Mania de explicação, by Adriana Falcão and Mariana Massarani. This activity consists of the elaboration of Dictionaries - Bizarre Dictionaries - by students of Technical Courses Integrated to High School whose entries, and their respective meanings, sound like poems and are poetic fragments of their experiences. In the first moment of the text, it is presented a history of the proposal, reflections on this book and the teaching of Portuguese language and literature, addressing motivations, difficulties and considerations about the activity developed. In the second moment, based on the concept of experience, by the teacher and researcher Jorge Larrosa (2002), it is made an analysis of some works done by students of this federal school and explored the meanings elaborated in their dictionaries.

Keywords: Bizarre Dictionary. Experience. Literature and teaching.

Recebido em: 02/02/2018

Aceito em: 05/02/2018

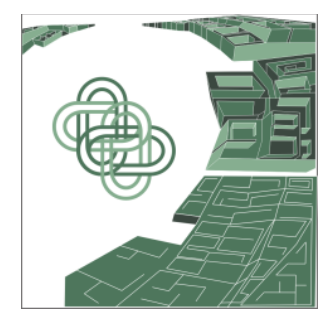

